\title{
Research on Packer Material Stress Analysis
}

\author{
Wang Jianning \\ Petroleum Production Engineering Research Institute \\ Huabei Oilfield Company \\ Renqiu,China \\ cyy wangjn $@$ petrochina.com.cn
}

\author{
Han Xinde \\ Petroleum Production Engineering Research \\ Institute,Huabei Oilfield Company \\ Renqiu,China
}

\author{
Wang Juan \\ The First Exploitation Factory,Huabei Oilfield \\ Company, \\ Renqiu,China
}

\section{Wang Li}

Exploration and Development Research Institute, Huabei Oilfield Company,Renqiu,China

\author{
Sui Lixin, Ning Jianjie, Yao Wang, Yan Jiang \\ Petroleum Production Engineering Research \\ Institute,Huabei Oilfield Company, \\ Renqiu,China
}

\author{
Xiongyi Hu \\ GangHua Survey Planning \& Design \\ Co.Ltd,Huabei Oilfield Company \\ Renqiu,China
}

\author{
Tao Sun \\ Petroleum Production Engineering Research \\ Institute,Huabei Oilfield Company \\ Renqiu,China
}

\begin{abstract}
Stress conditions of downhole packer are more complicated. Based on the packer structure and the environment the metal material exposes, this paper establishes proper numerical simulation model. And ANSYS software is utilized to carry out finite element analysis of built-up model to obtain stress distribution of metal material. On the basis of stress evaluation of metal material, stress of specific metal parts is analyzed and conformity of packer is determined. Furthermore, corresponding optimization is performed based on the results of stress analysis, which provides theoretical reference for the future structural design of packer.
\end{abstract}

Keywords- Finite element model; Material nonlinearity; Discrete model; Inner central tube; Steel setting sleeve.

\section{INTRODUCTION}

As one major downhole tool for oil exploration and development, packer is widely used in various fields of oil production technology. Therefore, the operating performance of packer has a direct impact on the economic benefits and oil production costs. Over past decades, along with the development of drilling and production technology towards high temperature, high pressure and complex deeper formations, more requirements for packer performance are put forward. As a key tool for oil production, packer has to meet the following demands: higher performance, multi-purpose, adaptability to various operation conditions, longer service life, simpler design, large diameter and more elastic recovery of sealing materials. For packer design, the application of computer simulation technology reduces the development costs of packer and shortens the development cycle as well as improves the reliability and overall performance.

Because the majority of complex packer parts are nonstandard and non-universe, the stress analysis is difficult to be done by using existing manuals and conventional analysis methods. In view of this, the study on the mechanics of the downhole packer is performed by using finite element method in this paper. Simulation test is carried out by simulating operation behavior of downhole packer in analog wells. According to the packer structure and the environment the metal material exposes, proper numerical simulation model is established. And ANSYS software is utilized to carry out finite element analysis of built-up model to obtain stress distribution and stress evaluation of packer metal material at high temperature and high pressure. On the basis of stress evaluation of metal material, stress of specific metal parts is analyzed and conformity of packer is determined. Furthermore, based on the results of stress analysis, corresponding optimization is performed to achieve optimal allocation of separate injection tools. The analysis results provide important theoretical basis for design and application of packer and play significant role.

\section{BASIC StRUCtURE AND FUnCTIONS OF PACKER}

Stress analysis of Y341-114 (Fig. 1) type water injection packer material is performed in this paper. This packer mainly consists of four parts such as 
sealing, setting, locking and unsetting. And each part respectively contains several components.

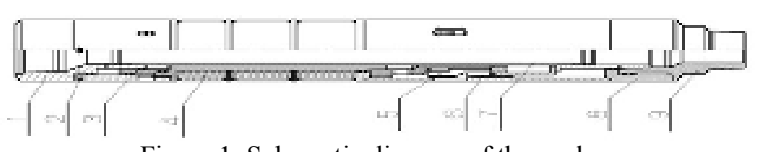

Figure 1. Schematic diagram of the packer

1-Upper joint;2-Unsetting shear pin;3-Backwash valve;4-Rubber cy linder;5-Locking mechanism;6-Outer cylinder;7-Center tube;8-Setti ng mechanism:9-Lower ioint

Above of all, the operating principle of packer is briefly introduced. The operational mode of the packer includes setting, sealing and unsetting.

Setting Process: When the packer runs to the planned depth, the pressure is built inside the tubing. Foreign fluid respectively acts against upper and lower pistons via inner and lower center tube holes to push the upper piston and the piston sleeve upgoing. When oil pressure reaches certain value, the shear pin is cut off and the lower piston runs upward, thus, to push upper piston and lower rubber cylinder seat upward to compress the rubber cylinder. Meanwhile, outer center tube promotes the claw to a certain distance, the claw sawtooth buckle engages with locking spring sawtooth buckle. After pressure relief, the cone opens up the locking spring. The locking spring locks tightly with claw. Setting process completes.

Sealing Process: When the packer sealing bears upward differential pressure, top fluid will directly run into top balance piston chamber to form upward force to balance the upward differential pressure of packer. When the packer sealing bears downward differential pressure, bottom fluid will run into balance piston chamber to form downward force. Simultaneously, the setting piston drives lower rubber cylinder seat to directly compress the rubber cylinder, which can ensure packer sealing effect.

Unsetting Process: When the upper joint is lifted, the latch finger moves to off-lock position, latching is released and the rubber cylinder rebounds. Unsetting process completes.

\section{Finite ElEMENT Method FOR NONLINEAR PROBLEMS}

Finite element method is one novel and effective numerical method which adapts to use of computer. Essentially, this method idealizes non-individual body with infinite degree of freedom as element aggregation with only finite degree of freedom, which can simplify the problems as structural problems suitable for numerical solution.

Generally, nonlinear problems include material nonlinearity and geometric nonlinearity. If system nonlinearity results from the nonlinearity of relationship between stress and strain of material, it is called material nonlinearity. If the displacement of the structure remarkably changes the stress state of the system, resulting in the linear system analysis method can not be used, it is called geometric nonlinearity.
Methods for nonlinear problems, which are quite different from solution of linear equations, include incremental method, iterative method and hybrid method. It is noteworthy that the structure balance actually achieves after structure deformation. Particularly for nonlinear problems, the structure balance equation must be established on the basis of state after structure deformation and the basic problem is to obtain balance state at current load. If the acting load is described as a function of time, the balance equation of object finite element discrete system can be expressed as:

$$
p^{\mathrm{t}}-f^{\mathrm{t}}=0
$$

In which:

$p^{\mathrm{t}}$ - external load nodal force vector at $\mathrm{t}$ (time) ;

$f^{\mathrm{t}}$ - nodal force vector at $\mathrm{t}$ (time) caused by element stress. All nonlinear effects should be taken into consideration.

Geometric properties or material properties of nonlinear problems is related with the path or time. Therefore, incremental analysis method is always used to solve nonlinear problems. The basic idea for incremental step-by-step method is to assume that the solution at $\mathrm{t}$ (time) is known, $\Delta \mathrm{t}$ is selected time increment. Thereby, at $\mathrm{t}+\Delta \mathrm{t}$ (time):

$$
P^{t+\Delta t}-f^{t+\Delta t}=0
$$

The solution at $\mathrm{t}$ (time) is known, thus:

$$
f^{t+\Delta t}=f^{\mathrm{t}}+f \quad f=K^{t} u
$$

In which:

$f$ - nodal force incremental vector caused by element internal stress incrementwithin time interval from $\mathrm{t}$ to $\mathrm{t}+\Delta \mathrm{t}$;

$K^{t}$ — tangent stiffness matrix of material and geometric conditions from $\mathrm{t}$ to $\mathrm{t}+\Delta \mathrm{t}$;

$u$ - node displacement increment within $\Delta \mathrm{t}$ interval.

Formula $u^{t+\Delta t}=u^{t}=u$ could be derived from above equation. According to $u^{t+\Delta t}$, stress at $\mathrm{t}+\Delta \mathrm{t}, f^{t+\Delta t}$ and $K^{t}$ $+\Delta t$ could be calculated for next iterative computation. For the purpose of accuracy, sufficient iteration numbers should be taken. The iterative method most commonly used in concrete computation is modified Newton iterative method. This method can be derived from Newton - RaPhsonew solution of nonlinear equations. Within the step size from time $f$ to $\mathrm{t}+\Delta \mathrm{t}$, iterative formula for modified Newton method can be expressed as:

$$
\begin{gathered}
K^{t} \Delta u_{i}=q^{t+\Delta t}-f_{i-1}{ }^{t+\Delta t} \\
u_{i}{ }^{t+\Delta t}=u_{i-1}{ }^{t+\Delta t}+\Delta u_{i}
\end{gathered}
$$

In which:

$i$-The number of iteration steps, taken $1,2, \ldots \ldots$ in turn. The initial value used for iteration is right the solution at $\mathrm{t}$ (time):

$$
u_{0}{ }^{t+\Delta t}=u^{t} \quad f_{0}{ }^{t+\Delta t}
$$


Right part in formula (4) is called unbalanced load before iteration of step $i$. In iterative process, $f_{i-1}{ }^{t+\Delta t}$ gradually approaches towards $P^{t+\Delta t}$ with $i$ increase. When the given precision target of unbalanced load is reached, iteration process terminates.

Based on the above rationale, discrete models for all parts of the packer are established. The finite element equation is built up according to packer operation process, thereby, performance parameters of packer are solved in setting, sealing and unsetting process.

\section{PACKer GeOMetric Model}

By studying the structure, principle and functions of downhole packer, the stress analysis of key parts, packer sealing property and overall system security are key factors in research. Packer mechanical model needs to be established to carry out corresponding stress analysis and calculations. For the purpose of packer mechanical analysis and building up finite element model for stress analysis and calculation of the main components, the first step needs to build three-dimensional geometric model for the corresponding components.

By analyzing the packer design, we can see that the downhole packer includes such three parts as sealing, setting and unsetting. According to respective specifications and dimensions, we use three-dimensional CAD drawing to build a three-dimensional geometry of main components of the packer. Three-dimensional geometric models of packer inner center tube and setting steel sleeve are shown as below.

Wherever Times is specified, Times Roman or Times New Roman may be used. If neither is available on your word processor, please use the font closest in appearance to Times. Avoid using bit-mapped fonts if possible. TrueType 1 or Open Type fonts are preferred. Please embed symbol fonts, as well, for math, etc.
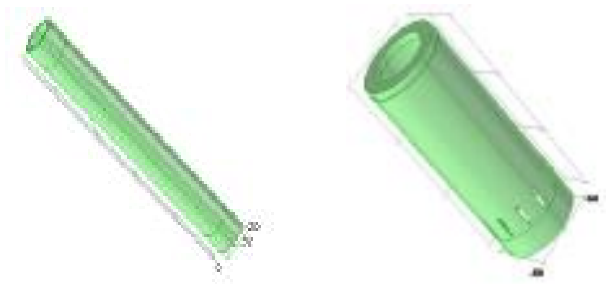

Figure 2. Inner center tube (left) and setting steel cover (right) th ree-dimensional geometric models

\section{Downhole Packer Stress Analysis}

According to packer structure, various operation modes such as running, setting, backwash, water injection and unsetting are taken into consideration, the following stress analysis and calculation are conducted:

\section{A. Running Process}

Pressure balance and values of tubing and casing are linked with well depth. Packer presents intermittent accelerated falling state, mainly due to the lower liner gravity, fluid inertia force as well as frictional resistance of casing wall and annulus fluid. Amongst, all forces except the liner gravity are unfavorable for packer running. Fluid inertia force inside the tube will apply to the setting piston and annulus fluid will create trapping pressure to compress rubber cylinder when string runs down rapidly. Such occurrence will lead to halfway setting of packer. Therefore, such dangers should be taken full account in packer design and setting mechanism should be prelocked. It may be considered that the packer bears the weight of lower liner alone (liner length $\leq 200 \mathrm{~m}$ ) and now the affected parts of packer are inner center tube, lower center tube and lower joint. Applied pulling force is approximately $20 \mathrm{KN}$.

\section{B. Setting Process}

Setting pressure is $8 \mathrm{MPa}$. Casing pressure is related with well depth. Packer presents short distance and slow moving down state. The packer primarily bears fluid pressure inside the tube and liner gravity. When the packer runs to planned well depth, tubing pressure is built, setting activity is performed and verification of string sealing is conducted. Such tension members of packer as inner center tube, lower center tube and lower joint are involved. Pressure bearing parts include outer sleeve, upper and lower rubber cylinder seats as well as upper and lower pistons, etc.. From the design chart, it can be seen that the inner center tube suffers from the maximum pulling force and setting steel sleeve suffers from the maximum compression force. Thus, only inner center tube and setting steel sleeve are checked. When the setting pressure is $8 \mathrm{MPa}$, the maximum differential pressure the cylinder can bear is $35 \mathrm{MPa}$. Therefore, it is calculated by $35 \mathrm{MPa}$.

The pulling force that inner center tube suffers is the sum of pulling force generated by fluid pressure inside tubing and liner gravity:

$$
\begin{aligned}
F_{2}=\pi / 4 \times d_{0}^{2} p+2 \times \pi / 4 \times\left(d_{2}^{2}-d_{1}^{2}\right) p+w \\
= \\
\quad \pi / 4 \times 0.062^{2} \times 35 \times 10^{6}+2 \times \pi / 4 \times\left(0.136^{2}-0.080^{2}\right) \\
\quad \times 35 \times 10^{6}+19.2 \times 10^{3} \\
=792.0 \mathrm{KN}
\end{aligned}
$$

The pressure applied to upper piston sleeve is the pressure generated by lower piston:

$$
\mathrm{F}_{3}=\pi / 4 \times\left(d_{2}^{2}-d_{1}^{2}\right) p_{1}
$$

$$
=\pi / 4 \times\left(0.136^{2}-0.080^{2}\right) \times 35 \times 10^{6}
$$

$$
=332.5 \mathrm{KN}
$$

The pressure applied to setting steel sleeve is thrust of 2 stage piston:

$$
\mathrm{F}_{4}=2 \times \mathrm{F}_{3}=665.0 \mathrm{KN}
$$

In which:

$d_{0}$ - Inner diameter of inner center tube ;

$d_{l}$ - Inner diameter of upper and lower pistons;

$d_{2}$ - Outer diameter of upper and lower pistons.

\section{Well Backwashing Process}


Backwash pressure is approximately $1 \mathrm{MPa}=$ casing pressure - tubing pressure. Because all stages of packer are on setting status, friction force between the rubber cylinder and casing can balance out portion of the rear weight, and also tubing casing pressure difference is smaller, the packer steel body stress is small at this moment.

\section{Injection Process}

Surface injection pressure differential is up to $35 \mathrm{MPa}$. All parts of the packer is applied stress less than the stress when setting, so it is unnecessary to recalculate.

\section{E. Unsetting process}

Packer primarily bears fluid pressure in tubing and liner gravity. The main task is to overcome friction forces of packer rubber cylinder and other tools. During trip-out, the packer presents intermittent positive movement with variable velocity and bears mainly lower liner gravity. This packer is unset by pulling tubing upward, and there does not exist tubing casing pressure difference when unsetting, so the packer steel body in this process bears forces less than those abovementioned.

The above analysis shows that the maximum pulling force applied to inner center tube is $792.0 \mathrm{kN}$ and the maximum pressure applied to setting steel sleeve is 665.0 $\mathrm{kN}$ during setting process. Finite element analysis of inner center tube and setting steel sleeve is conducted in this paper, to search out the stress distribution law of such two parts at the most dangerous working conditions.

\section{InNer CEnter Tube Finite ElEMENT ANAlysis}

Packer stress analysis tells us that inner center tube and setting steel sleeve among of packer rigid elements suffer from the maximum stress in operations. Finite element analysis of these two parts are as follows.

Three-dimensional geometric model is established using CAD software. And then this model is introduced to finite element software. Using high precision tetrahedron 10 -node elements divides finite element grid of this model and refines such details as bevel edge, etc.

TABLE I. MATERIAL AND MECHANICAL PARAMETERS OF INNER CENTER TuBE

\begin{tabular}{|c|c|c|c|c|c|}
\hline $\begin{array}{c}\text { Descri } \\
\text { ption }\end{array}$ & Material & $\begin{array}{c}\text { Elastic } \\
\text { Modulus } \\
\text { E/GPa }\end{array}$ & $\begin{array}{c}\text { Poisson' } \\
\text { s Ratio } \\
\boldsymbol{\mu}\end{array}$ & $\begin{array}{c}\text { Yield } \\
\text { Limit } \\
\mathbf{M P a}\end{array}$ & $\begin{array}{c}\text { Ultimate } \\
\text { Strength } \\
\mathbf{M P a}\end{array}$ \\
\hline $\begin{array}{c}\text { Center } \\
\text { Tube }\end{array}$ & $\begin{array}{c}\text { N80 } \\
\text { ng } \\
\text { ng }\end{array}$ & 206 & 0.3 & $\begin{array}{c}552 \sim \\
758\end{array}$ & $\geq 689$ \\
\hline
\end{tabular}

Under setting conditions, $15 \mathrm{MPa}$ fluid internal pressure acts against inner wall of the tube. $19.2 \mathrm{kN}$ hanging weight acts upon lower thread flank. The upper end is connected with upper joint. The longitudinal displacement of thread flank is zero (axial).

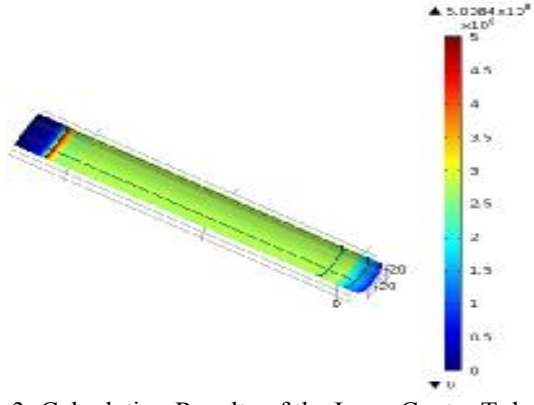

Figure 3. Calculation Results of the Inner Center Tube During Setting

The calculation results of inner center tube finite element is shown in Figure 3, which shows:

A. The center section stress of inner center tube ranges from 250.4 to $280.6 \mathrm{MPa}$ (light cyan), and both ends stress ranges from 37.48 to 74.11 MPa (light blue);

B. Stress concentration occurrs at rear end of upper thread, which is up to $500.8 \mathrm{MPa}$.

Thus, the stress distribution of inner center tube demonstrates that the stress concentration mainly occurrs at transition section of thread end. From the aspect of uniform stress distribution, using arc transition would be more beneficial for stress transfer. Therefore, such structure as bevel edge or arc can be adopted to reduce the stress concentration and improve the mechanical properties of the center tube.

\section{Setting Steel Sleeve Finite Element ANALYSIS}

During setting process, the load against setting steel sleeve is mainly setting load passedin the order of piston, lower rubber cylinder seat, rubber cylinder and upper rubber cylinder seat. By mechanical analysis, when packer pressure is $15 \mathrm{MPa}$, the total force applied to setting steel sleeve is $285 \mathrm{kN}$, which acts upward against lower end face. The longitudinal displacement of thread flank at connection point of upper end and upper joint is zero(axial).

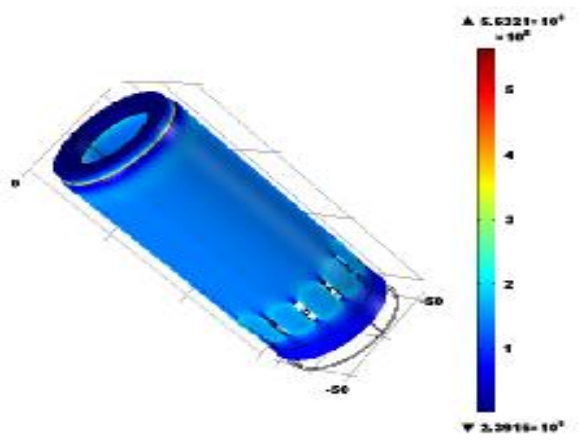

Figure 4. Calculation Results of Setting Steel Sleeve Finite Element

The calculation results of setting steel sleeve finite element is shown in Figure 4, which shows:

A.During setting process, majority of stress on setting steel sleeve is within $150 \mathrm{MPa}$. There exists greater stress at both ends of the grid shaped water inlet opening and local stress reaches $220 \mathrm{MPa}$ or 
so. Stress concentration occurs locally at the grid shaped water inlet opening.

B.The stress mainly concentrates on top of arc of grid shaped water inlet opening close to rubber cylinder seat. It is caused primarily by abrupt stress change around the grid shaped water inlet when setting steel sleeve bears pressure, because the grid shaped water inlet above the setting steel sleeve is like the crack on cylinder surface of steel sleeve.

C.In order to improve the stress distribution on the grid of water inlet opening, and to reduce or avoid damages to parts by stress concentration at both ends of grid water inlet opening, the curve shape at both ends of opening can be properly changed or the opening numbers can be reduced.

Packer mechanics and finite element analysis can help us find out packer mechanical properties and distribution law in operations, as well as improve the structure of parts bearing more forces. Such analysis provides theoretical basis and foundation for improvement of existing structure of the packer, development of new packer and simulation research on operation behavior of packer.

\section{CONCLUSIONS}

Based on applied research on the packer home and abroad, especially on stress of metal material under working conditions, this paper utilizes finite element method to study the mechanical properties of packer. Furthermore, this study provides theoretical reference for packer structural design optimization.

By finite element analysis of center tube and setting steel sleeve, stress distribution of center tube and steel sleeve during setting process is obtained: the stress concentrates at transition section of center tube thread and around grid water inlet above setting steel sleeve. Therefore, bevel edge or arc structure can be adopted to reduce stress concentration at transition section of center tube thread and improve the mechanical properties of the center tube. For setting steel sleeve, number of grid openings can be reduced to release stress concentration.

\section{ACKNOWLEDGMENT}

China National Petroleum Corp., a major scientific and technological projects: Huabei Oilfield Company produced $8,000,000$ tons stable Key Technology Research and Application (Number: 2014E-35) funding.

\section{REFERENCES}

[1] Ma Xueyong, Li Junliang," Stress analysis of water injection string in varying processes,"Journal of Oil and Gas Technology,No.4,vol.28,Aug.2006,pp.373-375.

[2] Lian Zhanghua,Yue Bin,Song Zhoucheng,and Li Tiejun,"Finiteelement simulation analysis of the packer during setting process."'China Petroleum Machinery ,No.9,vol.35,2006,pp.1921,41 .

[3] Zhao Mingchen,"Analysis of Force Applied on Zoning Water Injection Packer."Journal of Yangtze University(Natural Science Edition) ,No.4,vol.8,Apr.2011,pp.59-62.

[4] Liao Yuhua,Yang Bin,and Li Min. .Mechanic model analyses of packer string effect.Machinery,2012.s1

[5] Wang Ying,Jia Shaoshan,"Virtual Prototype Construction and Simulation Study of Packer,"Oil Field Equipment,No.8,vol.37,2008,pp.45-47.

[6] Xia Chengyu, Li Wanbin,Feng Yijing,Liu Xuhui,,Gan Lu,and Feng Ding,"Research on the Setting Mechanism of Multilayer Packer,"China Petroleum Machinery,No.2,vol.42,2014,pp.49-52.

[7] Zhang Ruijin,Wang Weiyang,"Layered water injection pipe string mechanics analysis and condition diagnosis technology and development,"Neijiang Science \& Technology,2012.1,pp.27,81.

[8] Shen Xiaoli, Chen Lihai,Wang Zijian,ang Cao Rongrong,"Research on Multiple Gradually-Releasing Injection Packer," Oil Field Equipment ,No.4,vol.43,2014,pp.71-73.

[9] Li Qindao,Xie Guangping,and Zhang Juan," Force analysis of permanent packer string," Drilling \&Production Technology ,No.2,vol.25,2002,pp.53-57.

[10] Li Qindao,Xie Guangping, and Zhang Juan,"Computational analysis of mobile packer string deformation quantity,"Drilling \& Production Technology,No.1,vol.25,2002,pp.60-64.

[11] Y.Chen, Sarmad Adnan," Buckling of Pipe and Tubing Constrained Inside Inclined Wells," presented at the 25th Annual Offshore Technology Conference in Houston,TX,May 36,1993,pp.613-617, OTC7323. 